\title{
SINGLE SIDED SINGLE PASS SUBMERGED ARC WELDING OF AUSTENITIC STAINLESS STEEL
}

\section{K.Chi ${ }^{1}$, M.S.Maclean, ${ }^{1}$ N.A.McPherson ${ }^{2}$ and T.N.Baker ${ }^{1}$}

${ }^{1}$ Metallurgy and Engineering Group, Department of Mechanical Engineering, University of Strathclyde, Glasgow, G1 1XJ, United Kingdom

${ }^{2}$ BAE Systems - Naval Ships, 1048 Govan Road, Glasgow, G51 4XP, United Kingdom

Abstract

The weld metal produced from a series of high productivity welds of $316 \mathrm{LN}$ austenitic stainless steel plate was examined to evaluate the effects of the use of a higher heat input process $(>2.5 \mathrm{~kJ} / \mathrm{mm})$. This high heat input process was aimed at maximising single sided weld metal penetration in a single pass using simple square edge preparations and minimising time consuming handling operations. The evaluation was undertaken by correlating the local microstructure with the local toughness and microhardness of the cap, middle and root of the weld. It was established that the intermetallic phases / carbides present did not appear to have a significantly adverse effect on either corrosion or toughness. The phases observed and confirmed by the use of SAED were predominantly chi $(\chi)$ with some sigma( $\sigma)$. No identifications were made of $\mathrm{M}_{23} \mathrm{C}_{6}$ which was observed in other studies of 316LN welds.

A series of impact tests with variations in the notch positions showed that the thickness of the delta ferrite had an effect on the weld metal toughness. As a result of this work it was established that similar volume fractions of delta ferrite did not necessarily produce similar levels of weld metal toughness, but ferrite thickness did appear to have a contributory effect.

Welding of $316 \mathrm{LN}$ stainless steel with a single sided single pass submerged arc welding process was satisfactorily undertaken up to $20 \mathrm{~mm}$ plate thickness without preheat or post weld heat treatment. The ability to achieve this resulted in significant 
economic savings within the process for ship panel production combined with satisfactory weld metal properties.

\section{Introduction}

'The 300 series of austenitic stainless steels has been widely used in the power, petrochemical and nuclear industries for components such as pressure vessels, boiler tubing, headers and steam piping In any such installations welded joints are a major concern' ${ }^{1}$.Many of these applications require the welded steels to be in service at temperatures above ambient. Therefore much of the earlier detailed microstructural work was undertaken to understand changes which occurred during either elevated temperature service or as a result of welding and post weld heat treatment. In many studies, the effects of elevated temperature on the properties and microstructure were followed by investigating the weld after ageing between 500 to $900^{\circ} \mathrm{C}$. There are extended compilations of references relating to previous studies on this subject, for example $\mathrm{e}^{1-3}$. Austenitic stainless steels also have a wide range of new applications including 316LN stainless steel in the construction of carriers for use in the marine transportation of chemicals ${ }^{4,5}$.In these applications, the welded steels are subjected to temperatures of ambient or below, and therefore it is the mechanical, toughness and corrosion properties of the as- welded steel which are of interest. In addition to new applications, major changes have occurred in the welding process route. These changes in turn will influence the microstructure and properties of the weld and it is this area with which the present paper is concerned.

One of the requirements of most austenitic stainless steel welds is that there is sufficient delta ferrite present in the microstructure, to counteract any tendencies to solidification cracking ${ }^{1,6}$. This is to ensure that in areas susceptible to cracking, 
elements such as sulphur and phosphorus, which are known to be associated with cracking problems, can dissolve in ferrite rather than precipitate in austenite. The maximum solubility of sulphur and phosphorus in delta ferrite is $0.18 \%$ and $2.8 \%$ respectively, compared to that in austenite which is $0.05 \%$ and $0.25 \%$ respectively. Further, it has been shown that the absence of delta ferrite can cause longitudinal solidification cracking in the weld metal ${ }^{7,8}$. On the other hand, high concentrations of delta ferrite also cause problems. Ahblom and Sandstrom ${ }^{9}$ have reported that large volume fractions of ferrite in austenitic stainless steel can give rise to a decrease in the hot workability, and by inference, the ductility. As a result of this potential conflict, it is normal to specify that delta ferrite in the range $5 \%$ and $10 \%$ should be present in the weld metal microstructure ${ }^{1,3}$.Empirical approaches have been developed to estimate this range, based on the chemical composition of the steels, and these have been primarily attributed to Schaeffler ${ }^{10}$ and Delong ${ }^{11}$. These methods have involved plotting a nickel equivalent against a chromium equivalent, knowing the parent plate chemical composition, the welding consumable composition and the relative dilutions of the parent plate. From this data, the approximate delta ferrite content and the microstructural phases can be read off a series of ferrite lines and phase boundaries in the diagram. It has been recognised for some time, that although the diagrams are good indicators, factors such as cooling rate were not taken into account and it is well known that the cooling rate can dramatically change the microstructure ${ }^{12}$.As an example, a root welding pass can be welded against a ceramic tile or a backing bar filled with flux. The overall insulating effects in that region would create slower cooling conditions than those in the weld cap where, in some instances, the solidifying metal can be exposed to the atmosphere. Further refinements in predicting delta ferrite levels in austenitic stainless steels have been developed using Bayesian 
Neural Networks $(\mathrm{BNN})^{13}$, where the potential impact of elements such as vanadium, titanium and silicon, and intra-element interactions have been included, and importantly, cooling rate ${ }^{14,15}$.

The decomposition of delta ferrite has been discussed extensively in the literature, for example $\mathrm{e}^{1-3,16,17}$.The higher chromium content of delta ferrite can lead the weld metal to be more prone to decomposition than the parent plate. When decomposition takes place, carbides and intermetallic phases form with compositions which are dependent on the conditions at the time. There has been considerable debate about the role of intermetallic phases in stainless steel weld metal. Currently, there is evidence to show that around $2 \%$ volume fraction of intermetallic phases is tolerable ${ }^{18}$ and more recently ${ }^{19}$ it has been reported that up to $2.8 \%$ can be tolerated in super-austenitic stainless steel with only a marginal deterioration in properties. $316 \mathrm{LN}$ stainless steel which is the subject of the present study, has an addition of up to $0.14 \% \mathrm{~N}$. Nitrogen is added to enhance strength at room temperature, and also to reduce the rate of chromium carbide precipitation and therefore the susceptibility to sensitization ${ }^{20}$. The low carbon content will also reduce the tendency to carbide formation. The level of the heat input, which is controlled by the welding parameters such as the arc energy, is also important. There are economic advantages in some instances of welding using high heat inputs. Honeycombe et $\mathrm{al}^{21}$ investigated the high arc energy submerged arc welding of austenitic stainless steels using arc energies up to $6 \mathrm{~kJ} / \mathrm{mm}$. They found that at higher levels of heat input, satisfactory tensile properties and impact toughness could still be achieved with $316 \mathrm{~L}$ and 347 grades. Very little of this work focussed on single sided, single pass square edge weld preparation welding, although a $13.5 \mathrm{~mm}$ butt of 347 material was welded using a heat input of between 2.7 and $3.0 \mathrm{~kJ} / \mathrm{mm}$. 
It is therefore important to establish a quantitative or semi-quantitative description of the relationship between the phases present and the properties of the weld for different weld configurations and heat input. The objective of the current study is to undertake this for a square edge weld preparation using a high heat input. It also focuses on how far the existing processes can be modified to improve productivity while retaining satisfactory properties and microstructure.

There have been several attempts to relate the microstructure of austenitic stainless steels to the proof and tensile strength as a means of predicting these properties from composition and microstructural parameters . They have been reviewed by Gladman and Pickering ${ }^{22}$.The empirical equations they discuss include parameters such as the average austenite grain size and the volume fraction of delta ferrite. However, no such relationships are given to predict the Charpy toughness of austenitic stainless steels as are found for low carbon steels ${ }^{22}$. 'Stainless steels welds are known to fail exclusively by a dimple rupture mechanism, where the micro-voids nucleate at inclusions and delta ferrite particles. Thus the overall fracture resistance is controlled by the density and morphology of second phase particles. Because delta ferrite is ductile at ambient and elevated temperatures, its volume fraction and morphology do not control the fracture response. The fracture properties are controlled by the density of manganese silicate inclusions. However, at cryogenic temperatures, where significant ductility loss can occur, delta ferrite is brittle and can degrade the fracture resistance of the weld. A ductile -brittle transition temperature phenomenon is observed. Cleavage fracture of the delta ferrite creates a network of micro-cracks ahead of a crack front ${ }^{23}$. How high above $-296 \mathrm{~K}$ these conditions still prevail is not known. 


\section{Background}

The marine transportation of chemicals creates its own set of specific requirements, the main one being corrosion resistance of the parent plate and the weld metal ${ }^{4,5}$. There is no current requirement to meet any specific levels of toughness in this application. In this extremely competitive market sector, quality and cost are of major significance, and there are constant demands to establish cost effective process routes for the fabrication of chemical carriers. One such area has been the replacement of 316LN with duplex stainless steel ${ }^{5}$ Partly in response to these challenges, the submerged arc welding (SAW) process for austenitic stainless steels has been identified as an area where cost benefits can be gained. Instead of using a conventional Y preparation, a square edge weld preparation has been used. This reduces the number of burning cuts required to produce the weld preparation from two to one. In addition, the number of weld passes is typically reduced from four to one, and the turning over of the stainless steel panel to carry out the second side welding has been eliminated. Earlier work ${ }^{4}$ using a square edge weld preparation with one SAW pass from either side of the plate was found to be successful when assessed against the previously mentioned criteria. Data published by Gowrisanakar et al ${ }^{24}$ has indicated that increasing the number of submerged arc welding passes on $316 \mathrm{~L}$ stainless steel resulted in deterioration in the weld metal ductility and impact properties. This was attributed to morphological changes caused by the reheating and cooling effects of subsequent passes, in the previously deposited weld metal. Improvements in productivity through higher welding speeds can be obtained with a twin wire process with additional benefits through lower heat input and reduced distortion potential. The use of multi- wire submerged arc welding is not a new practice and one of the earliest references to twin wire submerged arc welding was in 
$19544^{25}$. Significant work has been carried out on carbon steels, where it has been a well established process for a number of years, for example in pipe mills. In this process the leading wire is direct current electrode positive (DCEP) to facilitate deep penetration, and the wire angle is normally $90^{\circ}$ to the work piece, which also benefits penetration. Further benefits in penetration can be obtained using a smaller diameter welding wire. The trailing wire is operated on an alternating current (AC) mode, which allows the weld pool to spread, and is ideal for filling the remainder of the weld. Interaction between the arcs is also reduced by the use of AC for the trailing wire. It is normal to use an angled trailing wire, spaced approximately $20 \mathrm{~mm}$ from the leading wire. The use of one-sided submerged arc welding using twin wires was developed by Ratzsch ${ }^{26}$ in the early 1980s. Since then a number of variations of the process have been introduced, such as the use of cored wires in place of, and in addition to solid wires, and the use of metal powder additions ${ }^{27}$.

The main aim of the current work was to establish economic benefits from the welding process, whilst maintaining the desired properties of the weld metal and the adjacent areas. In this specific instance, the use of a square edge weld preparation reduced the plate cutting time; the single welding pass removed the need to turn the welded panel for any second side weld; the time to return the welding carriage to the start position to start subsequent weld passes was removed and the total time was reduced by reducing the number of welding passes. A summary of these effects has been shown in Table 1, where the comparison with a conventional Y welding preparation results in an overall time saving of $78 \%$. When compared to the square edge preparation with two passes ${ }^{4}$, there is a $61 \%$ time saving. In addition to these savings, there is an equivalent saving in welding consumable costs, i.e. compared to 
the conventional welding preparation the saving is $75 \%$, and compared to the double sided square edge preparation, the saving is $50 \%$.

\section{Experimental}

Austenitic stainless steel test pieces with dimensions 1200 × $300 \times$ T mm, where T was, $10: 15: 20 \mathrm{~mm}$, were produced using single sided submerged arc welding. The details of the relevant SAW parameters are given in Table 2. In each case the consumable used was a $3.2 \mathrm{~mm} 316 \mathrm{~L}$ solid wire in combination with a fibre backing tape against a copper cooling bar. A basic flux was used as the top flux. For the $20 \mathrm{~mm}$ thick plate welded with a twin wire procedure, both wires were solid, $3.2 \mathrm{~mm}$ diameter.

Table 3 shows the chemical analysis of each of the weld metals. In addition, the chemical analyses of the welding wire and that of typical $316 \mathrm{LN}$ plate ${ }^{28}$ have been included. The composition of the basic flux was $15 \% \mathrm{SiO}_{2}: 35 \% \mathrm{Al}_{2} \mathrm{O}_{3}: 45 \% \mathrm{CaF}_{2}$ : $2 \% \mathrm{Na}_{2} \mathrm{O}: 2 \% \mathrm{~K}_{2} \mathrm{O}: 0.5 \% \mathrm{CaO}$. Table 3 also contains nickel and chromium equivalent data calculated on the basis of the published work of Delong et $\mathrm{al}^{11}$, which allows an estimate of the volume fraction of delta ferrite to be made. Another set of nickel and chromium equivalents developed by Suutala and Mosio ${ }^{28}$ have been calculated to allow the primary solidification mode (PSM) to be determined.

Mechanical testing was carried out in accordance with Classification Society Rules these required transverse tensile tests, hardness scans using the Vickers test with a $10 \mathrm{~kg}$ load, bend tests, macro etch, while the corrosion resistance was determined using an ASTM A 262 practice E test. In addition, a pair of longitudinal all weld metal tensile tests were carried out, along with a series of Charpy impact tests at various temperatures. The Charpy specimens, with the notch approximately in the 
middle of the weld metal, were standard $10 \times 10 \mathrm{~mm}$ for all the plate thicknesses except weld T10 which was tested using $7.5 \times 10 \mathrm{~mm}$ specimen cross sections. The results from the latter tests were factored up according to the standard system in Lloyds Register for the Classification of Ships. To relate the toughness data from different positions within the weld to the local microstructure and microhardness, Charpy impact specimens were taken from T 15 at the positions shown in Figure 1, which sample the cap, middle and root. Figure 1 also indicates the orientation of the notch. This has permitted a direct comparison to be made of the toughness data from the centre of the weld metal, shown in Table 4. Further hardness investigations were carried out using microhardness testing with a $100 \mathrm{~g}$ load. This allowed microhardness maps to be developed, showing local variations in hardness, which could be correlated with the corresponding microstructure. All the relevant test data have been summarised in Table 4.

Optical metallography was carried out on metallographically prepared specimens after etching using an electrolytic technique with $10 \% \mathrm{KOH} / 90 \%$ distilled water at an operating voltage of $3 \mathrm{~V}$. This method clearly revealed the delta ferrite, which enabled a determination of ferrite volume fraction to be made using a Nikon Epiphot optical microscope together with an Image-Pro plus version 4.0 image analyser. The error was estimated to be $\pm 5 \%$. For each specific position in the weld - cap: middle: root, measurements on five fields at a magnification of $x 500$ were made and the measured data were analysed using an Excel programme. Quantitative metallography was carried out on three positions in T10 to measure the thickness of the delta ferrite within the networks. Approximately 500 measurements were taken for each position. Slices, $0.5 \mathrm{~mm}$ thick, were cut normal to the welding direction to allow specimens suitable for transmission electron microscopy (TEM) to be taken from a series of 
positions in the weld cross section. Discs, $3.0 \mathrm{~mm}$ in diameter were trepanned from specific positions in the weld metal as shown in Figure 2, by using an electric discharge machining system. The discs were then hand ground to a thickness of approximately $80 \mu \mathrm{m}$, and finally thinned with a twin jet polisher using a mixture of perchloric acid, acetic acid and ethanol in a1: 4: 1, ratio. The solution was maintained at ambient temperature whilst an applied voltage of $20 \mathrm{~V}$ was used to effect the thinning for subsequent examination in a Philips EM400T transmission electron microscope operating at either 100 or $120 \mathrm{kV}$.

Precipitates were identified from selected area electron diffraction patterns (SAED) and the interplanar spacings of Chi $(\chi)$, Sigma $(\sigma)$ and carbide phases were calculated using a CaRine Crystallography 3.1 software package.

Using TEM, a semi quantitative assessment, mostly on T10 and T15, was made of the degree of intermetallic and carbide precipitation which occurred on the $\delta / \gamma$ grain boundaries. All observations for this semi-quantitative description were made at a magnification of $x 22,000$. For each foil, the number of fields viewed and the grains containing delta ferrite were recorded, together with the severity of the precipitation. The positional correspondences for foil specimens in welds T10 and T15 are given in Figure 2 and the results are listed in Table 8.

\section{$\underline{\text { Results }}$}

\section{Chemical Analysis}

The weld metal chemical analysis in Table 3 does not show any specific major differences among the four specimens, except in the case of nickel, where the $20 \mathrm{~mm}$ thick weld analysis has a higher nickel content. This reflects a lower than predicted weld metal percentage delta ferrite content as calculated from the Delong diagram ${ }^{11}$. However, the effect of this on the primary solidification mode (PSM) shown in Table 
3 appears to be very slight. All the welds were predicted to solidify in a ferrite austenite (F-A) mode based on the classification developed by Suutala and Mosio ${ }^{28}$ .This was confirmed using the data developed by Inoue et al ${ }^{29}$ with a modified Schaeffler diagram.

\section{Mechanical and Impact Properties}

Mechanical test data given in Table 4 shows very few significant differences among the longitudinal tensile data for the four welds. A general decrease in the toughness with decrease in test temperature and increase in thickness is noticeable. This is, to some extent, reflected in the hardness data with the twin wire $20 \mathrm{~mm}$ thick welds having the highest root and cap hardness.

Figure 1 shows the portion of the weld metal involved in the impact test. Where the bulk of the root of the weld is excluded from the impact test specimen, the toughness appears to be better although there is some scatter in the individual results. The data for $-60^{\circ} \mathrm{C}$ in the top right position is lower than expected.

\section{Microhardness}

The average microhardness test results are shown in Table 5. Because the width of the $\delta$ ferrite did not allow a microhardness indent to be placed solely in this phase, using the measured average hardness of the weld metal in a given area together with the measured microhardness of austenite and the volume fractions measured in the same area of both austenite and delta ferrite and given in Figure 3, the hardness of the $\delta$ ferrite was estimated from equation (1)

$$
\mathrm{H}=\mathrm{H}_{\gamma} \mathrm{f}_{\gamma}+\mathrm{H}_{\delta} \mathrm{f}_{\delta}
$$

where

$$
\begin{aligned}
& \mathrm{H}=\text { average microhardness of the sample } \\
& \mathrm{H}_{\gamma}=\text { average microhardness value of austenite }
\end{aligned}
$$




$$
\begin{aligned}
& \mathrm{H}_{\delta}=\text { microhardness value of delta ferrite } \\
& \mathrm{f}_{\gamma}=\text { volume fraction of austenite } \\
& \mathrm{f}_{\delta}=\text { measured volume fraction of delta ferrite }
\end{aligned}
$$

While $\chi$ phase and carbides can have a significant effect on some properties, the volume fractions observed in this work imply that they make a negligible contribution to hardness.

For T15 cap, the average of 10 microhardness measurements in austenite $\mathrm{H}_{\gamma}$ is

$189 \mathrm{H}_{\mathrm{v}}$. From Figure $3, \mathrm{f}_{\delta}$ is 0.067 , which gives $\mathrm{f}_{\gamma}=0.933$, when the volume fractions of the intermetallics and carbides are negligible. $\mathrm{H}$ is therefore $199 \mathrm{H}_{\mathrm{v}}$. This is greater than the hardness given in Table $4,174 \mathrm{H}_{\mathrm{v}}$, which was obtained with a $10 \mathrm{Kg}$ load compared with $100 \mathrm{~g}$ which was used for the microhardness testing. Using this data, $\mathrm{H}_{\delta}$ is therefore of the order of $350 \mathrm{H}_{\mathrm{v}}$. It can be seen that the estimated hardness of the delta ferrite is about 1.8 times higher than that of the austenite matrix. By inference, the greater the proportion of delta ferrite in an area, then the higher will be the hardness. The average microhardness data compares reasonably well with the hardness data in Table 4 when the difference for the test load is allowed. As expected, the microhardness is higher.

\section{Metallography}

The delta ferrite volume fraction determined by optical microscopy is shown in Figure 3 for the T 10 and T 15 welds. Figures 4(a) - (d) are optical micrographs taken from the cap, middle and root of the T10 weld metal and are typical of what was seen in each of the welds being studied. Figure 3 shows a higher volume fraction of ferrite in the root of $\mathrm{T} 10$, which has approximately $38 \%$ more delta ferrite than in the cap area. This can be seen when comparing Figure 4(d) with Figures 4 (a) - (c). However, the 
same effect is not found in T 15. The measured values which are given in Table 3 are higher than those predicted from the Delong diagram. These predicted delta ferrite levels are an average of the whole weld metal, based purely on chemical composition, whereas those in Figure 3 are from specific areas within the weld. The delta ferrite had a discrete skeletal ferrite morphology ${ }^{30}$ but in some isolated instances, a network of delta ferrite was observed ${ }^{31}$, as shown in Figure 4(d). In addition, the width of the delta ferrite particles within the networks was measured. Figure 5 shows the data divided into top, middle and root of the weld. Over $90 \%$ of the measurements were in the range of 0.5 to $5 \mu \mathrm{m}$.

A typical delta ferrite microstructure in the cap of T15, is shown in Figure 6, which is a bright field TEM micrograph. There is no significant precipitation evident on the $\delta / \gamma$ grain boundaries. Another example from the middle -side position of T15 is shown in Figure 7 , where slight precipitation occurs along the $\delta / \gamma$ grain boundary. An example of what is called in this work dense discontinuous precipitation on the $\delta / \gamma$ boundaries and in a $\delta$ grain, is seen in T10 and shown in Figure 8.

Where no precipitates were found on the $\delta / \gamma$ grain boundaries, a high density of dislocations frequently existed with in the delta ferrite grains, Figure 9. Most precipitates formed along the $\delta / \gamma$ grain boundaries in the single and the twin wire welds were identified as $\chi$ phase, although there were exceptions. Only one particle of sigma phase was observed in T 10 in the cap area. This also formed on the $\delta / \gamma$ grain boundaries, and grew into the delta ferrite phase, Figure 10.

The $20 \mathrm{~mm}$ thick welds showed similar characteristics. Figure 11 is a bright field image from the $20 \mathrm{~mm}$ thick twin wire weld showing the presence of $\chi$ phase particles. A semi quantitative assessment of the degree of precipitation which occurred on the $\delta / \gamma$ grain boundaries was made using TEM, mainly on T10 and T15.For each foil, the 
number of fields viewed and the grains containing delta ferrite were recorded, together with the severity of the precipitation. This data is collated in Table 8 and shown in Figures 12 and 13.

\section{Discussion}

All the welds in this study were produced using a square edge preparation, which has the economic advantages highlighted in Table1, particularly through the shorter production time. Adopting this welding practice allowed satisfactory mechanical and toughness properties to be obtained in plate up to and including $20 \mathrm{~mm}$ thick. The data given in Table 4 and Figure 2 satisfies the test requirements of the Lloyds Register for the Classification of Ships.

The impact data in Table 4 and Figure 1 for weld T 15, with the exception of the top right area $-60^{\circ} \mathrm{C}$ data given in Figure 1 , shows that there is a satisfactory agreement between the testing undertaken according to Classification Society Rules and that from the samples which allowed more detailed testing. It can be seen that using the latter novel testing method, sampling different parts of the weld metal and not just the ,upper region as is the normal practice, there was a tendency for poorer toughness to be recorded when the root of the weld was an integral part of the material being tested. However, the data in Figure 3 for T 15 shows that there is no significant difference in the delta ferrite volume fraction among the three positions considered. It is interesting to note that the delta ferrite volume fraction in the root of weld $\mathrm{T} 10$ was the highest recorded of the three positions, but was still within the range normally accepted. Detailed quantitative optical metallography was carried out for T10 weld, on the three positions, cap, middle and root, which involved measuring the 
thickness of the ferrite within the networks. The resultant data is shown in Figure 5, and indicates that the ferrite was thicker in the root, having a mean thickness of $3.68 \mu \mathrm{m}$ compared with $2.28 \mu \mathrm{m}$ and $2.11 \mu \mathrm{m}$ for the middle and cap of the weld, respectively. Furthermore, $\sim 18 \%$ of the thickness measurements recorded for the root of weld T10 were greater than $8 \mu \mathrm{m}$, whereas for the cap and middle, this figure was $<2 \%$. So not only was the average thickness of ferrite in the root greater than the two other positions considered, but so was the \% delta ferrite with a thickness above $8 \mu \mathrm{m}$, which could lead to a higher possibility of crack initiation at low temperatures. This ferrite thickness data in turn relates reasonably well to the volume fraction data in Figure 3 for the T10 weld and is further evidence of the slower cooling rate in the root compared to the body of the weld. Assuming that a similar situation exists in the T15 welds, the poorer impact properties recorded by the Charpy specimens containing the root region, indicated by the data in Figure 2, can be understood. The effects on Charpy impact data of carbide precipitates and intermetallic phases in addition to delta ferrite are debatable, as previous work by some of the present authors ${ }^{16}$ did not produce a correlation between the volume fraction of precipitates and the toughness at low test temperatures of $316 \mathrm{LN}$ welds.

The data on the percentage of delta ferrite observed and the density of the intermetallic precipitates associated with the weld positions shown in Figure 2 and tabulated in Table 8, have been converted into graphical form as shown in Figures 12 and 13 for T 10 and T 15 welds respectively. This quite clearly shows that in both cases, the root has a high incidence of dense precipitation. Based on the precipitate identification, this is predominantly $\chi$ phase. The root of the weld will tend to cool down more slowly than the cap, as the root is welded against a backing flux which will act as an insulator. The slower cooling rate will favour the precipitation of phases 
such as $\chi$ phase $^{28}$. Furthermore, the higher the heat input, the greater the potential for more intermetallic phases to precipitate due to the slower cooling rate, which in effect mirrors the conditions explored in earlier work on aged welds ${ }^{1-3}$. It is known that initially on ageing $\mathrm{M}_{23} \mathrm{C}_{6}$ carbides precipitate at the $\gamma / \delta$ boundaries and after sufficient time at temperature, intermetallics including $\sigma, \chi$ and $\mathrm{R}$ phases have been observed to precipitate in the delta ferrite ${ }^{1-3}$.Weiss and Stickler ${ }^{3}$ showed that at higher ageing temperatures, $\mathrm{M}_{23} \mathrm{C}_{6}$ and $\chi$ phase were present. In our previous research on $16 \mathrm{~mm}$ thick $316 \mathrm{LN}$ welds, both $\mathrm{M}_{23} \mathrm{C}_{6}$ and $\chi$ phase were identified in the as-welded condition ${ }^{5}$.However, this work was carried out on multi pass welds where the reheating and cooling can produce conditions favourable for carbide precipitation. Also work on multi-pass $317 \mathrm{~L}$ welds identified $\chi$ phase as the only decomposition product of delta ferrite ${ }^{32}$. In the current investigation, while $\mathrm{M}_{23} \mathrm{C}_{6}$ carbide was not identified, $\chi$ phase and $\sigma$ phase were identified.

Gladman and Pickering ${ }^{22}$ in reviewing the influence of microstructure on the mechanical properties of austenitic stainless steels showed that average austenite grain size and the volume fraction of delta ferrite were important parameters in predicting the proof and tensile strength. However, they were unable to find empirical equations relating fracture toughness to microstructure. The toughness is an important parameter in assessing the welds in austenitic stainless steels which are to be in service at ambient and lower temperatures. It is known that in nitrogen strengthened steels, such as $316 \mathrm{LN}$, increases the strength particularly at low temperatures ${ }^{31}$.This increase in strength in nitrogen strengthened steels can tend to decrease the fracture toughness, In the present study, Charpy testing was undertaken down to $-100^{\circ} \mathrm{C}$, to provide an additional degree of confidence in the adopted welding procedure. While Charpy data is known to provide a wide scatter, for each of the positions of the weld tested, a 
progressive decrease in the absorbed energy was recorded. However, even the lowest energy, 39J, is well above that associated with delta ferrite which has been embrittled by for example precipitation on the $\gamma / \delta$ boundaries.

\section{Conclusions}

1 The current work has shown that significant productivity benefits can be realised by the single sided submerged arc welding of $316 \mathrm{LN}$ stainless steel using a high heat input and a square edge weld preparation. Adopting this welding practice allowed satisfactory mechanical, toughness and corrosion resistance properties to be obtained in plate up to $20 \mathrm{~mm}$ thick without preheat or post weld heat treatment.

2 A study of the local variations in the Charpy impact data between the cap, middle and root of the weld metal tested between -20 and $-100^{\circ} \mathrm{C}$, showed the root to have a slightly poorer toughness but still at an acceptable level.

3 The measured volume fractions of ferrite ranged between $6.7 \%$ and $11.0 \%$, compared to an estimate of 5\% from the Delong diagram, suggesting the advantages of using neural network model.

4 Local variations in the microstructure were observed, principally between the root and the cap of the welds particularly related to the ferrite thickness and the density of precipitation at the $\delta / \gamma$ phase boundaries.

5 Delta ferrite decomposition products identified by SAED were $\chi$ and $\sigma$ phases. A semi quantitative assessment established that there was a higher density of $\chi$ phase precipitation in the root compared to the cap of the weld metal.

6 The type, volume fraction and size of the current precipitates/phases in specific regions of the weld metal are tolerable, as indicated by the toughness data. 


\section{Acknowledgements}

The authors wish to thank the EPSRC for financial support for part of this work under Grant GR/M14029.

\section{References}

1 J.J.Smith and R.A.Farrar, Int. Mat. Revs., 1993,38, 25-51

2 B.Weiss and R.Stickler, Metallurgical Transactions, 1972, 3, 851-866.

3 P.Marshall, Austenitic Stainless Steels- Microstructure and Mechanical Properties,1984,Elsevier Applied Science Publishers, London.

4 N.A.McPherson, T.N.Baker, Y.Li and J.Hoffmann, Science and Technology of Welding and Joining, 2000, 5, 35-39

5 N.A.McPherson, K.Chi and T.N.Baker, Journal of Materials Processing Technology, 2003, 134, 174-179.

6 Ø. Grong, 'Metallurgical Modelling of Welding', 1997, Inst. Mat., p533

7 N.Suutala, T.Takalo and T.Moisio, Metallurgical Transactions A, 1979,10A, $512-514$

8 S.A.David, Weld. J., 1981, 60, 63s-71s.

9 B.Ahblom and R.Sandstrom, Int. Metals Review, 1982, 1, 1

10 A.L.Schaeffler, Metal Progress, 1949, 56, 680.

11 W.T.Delong, G.Ostrom and E.Szumachowski, Welding Journal, 1956, 35, 521s$528 \mathrm{~s}$.

12 J.M.Vitek and S.A.David, Weld. J., 1988, 67, 95s-102s

13 M.Vasudevan, A.K.Bhaduri, B.Raj and K.Prasad Rao, Journal of Materials Processing Technology, 2003, 142, 20-28.

14 J.M.Vitek, S.A.David and C.R.Hinman, Weld.J.,2003, 82 10s-17s.

15 J.M.Vitek, S.A.David and C.R.Hinman, Weld.J.,2003, 82 42s-50s. 
16 Y.Song, T.N.Baker and N.A.McPherson, Mater. Sci. Eng. A, 1996, A212, 228 234.

17 E.Folkhard, 'Metallurgieder Schweißung nichtrosender Stähle’; 1984, Berlin, Springer-Verlag.

18 L.Karlsson, Proc. Conf. Duplex Stainless Steels '97, Maastricht, The Netherlands, October 1997; Stainless. Steel World, 1997, 43058

19 S.Heino, E.M.Knutson-Wedel amd B.Karlsson, Materials Science and Technology, 1999, 15, 101-108.

20 Stainless Steels- ASM Handbook, 1994, ASM International, Materials Park, Ohio, p30.

21 J.Honeycombe, T.G.Gooch and J.A.Barlow, in 'New Developments Stainless Steel Technology’ 1984, Ed. R.A.Lula, Metals Park, Ohio, 319-340.

22 T. Gladman and F. B. Pickering in 'Yield, Flow and Fracture of Polycrystals', 188-198,1983, Ed T .N .Baker, Applied Science Publishers, London.

23 ASM Handbook, 'Fatigue and Fracture' 19, 1996,737

24 I.Gowrisankar, A.K.Bhaduri, V.Seetharaman, D.D.N.Verma and D.R.G.Achar, Weld. J., 1987, 56, 147s-154s.

25 T.Ashton, Weld. J., 1954, 33, 350-358

26 H.Ratzsch, ZIS-Mitteilungen, 1982, 14, 1105-1112

27 C.E.Thornton, Weld. J., 1988, 57, 342-345.

28 N.Suutala and T.Mosio: 'Solidification technology in the foundry and cast house', 310-314; 1980, Warwick.

29 H.Inoue, T.Koseki, S.Ohkita and M.Fuji, Science and Technology of Welding and Joining, 2000, 5, 385-396. 
30 J.A. Brooks, J. C. Williams and A. W. Thompson, Metallurgical Transactions A, 1983, 14A, 1271-1281.

31 J.A. Brooks, N. C.Y. Yang and J.S. Kraficik, Science and Technology of Welding and Joining, 2001, 6, 412-414.

32 Y. Song, N.A. McPherson and T.N.Baker, ISIJ Int. 1996,36,1392-1396. 


\section{Figures}

Figure 1 Positions of notches in $15 \mathrm{~mm}$ thick specimen for additional Charpy tests.

Figure 2 Schematic representation of position of TEM specimens

Figure 3 Ferrite volume fraction data related to position in the weld thickness for welds T10 and T15.

Figure 4 (a-d) Optical micrographs of delta ferrite in weld T10.

(a) Cap region, (b) Mid weld region, (c) \& (d) Root region

Figure 5 Delta ferrite thickness data for three positions through the thickness of weld T10.

Figure 6 Bright field TEM specimen showing delta ferrite with no precipitation. (Specimen C1 - weld T15)

Figure 7 Slight precipitation is shown at $\mathrm{P}$ on the $\delta / \gamma$ grain boundaries. (Specimen C9 - weld T15)

Figure 8 Dense discontinuous precipitation at the $\delta / \gamma$ grain boundaries (Specimen C7 - weld T15)

Figure 9 Example of high dislocation density in delta ferrite, where no grain boundary precipitation was evident. (Specimen C12 - weld T15)

Figure 10 TEM bright field showing delta ferrite( dark grain) with significant $\sigma$ precipitation both along the $\delta / \gamma$ grain boundary and within the grain, in specimen F3, weld T10.

Figure 11 Area in weld T20/2 showing $\chi$ phase particles 


\begin{tabular}{|c|c|c|c|c|c|c|c|c|}
\hline $\begin{array}{c}15 \text { mm thick } \\
\text { plate }\end{array}$ & Preparation & $\begin{array}{c}\text { Cutting } \\
\text { time } \\
\text { (mins) }\end{array}$ & $\begin{array}{c}\text { No. of } \\
\text { passes }\end{array}$ & $\begin{array}{c}\text { Turn } \\
\text { panel }\end{array}$ & $\begin{array}{c}\text { Welding } \\
\text { time } \\
\text { (mins) }\end{array}$ & $\begin{array}{c}\text { Additional } \\
\text { handling } \\
\text { time (mins) }\end{array}$ & $\begin{array}{c}\text { Total } \\
\text { time } \\
\text { (mins) }\end{array}$ & $\begin{array}{c}\% \text { time } \\
\text { saving }\end{array}$ \\
\hline Conventional & $\mathrm{Y}$ & 442 & 4 & Yes & 366 & 70 & 878 & \\
Two sided & ] [ & 67 & 2 & Yes & 230 & 50 & 347 & 61 \\
Single sided & ] [ & 67 & 1 & No & 126 & 0 & 193 & 78 \\
\hline
\end{tabular}

Table 1 Comparison of p[roductivity effects for three SAW modes of operation for a $15 \mathrm{~mm}$ thick plate

$\mathrm{Y}=\mathrm{Y}$ edge preparation

] [ = square edge preparation

\begin{tabular}{|c|c|c|c|c|c|l|}
\hline Weld & $\begin{array}{c}\text { No. of } \\
\text { wires }\end{array}$ & $\begin{array}{c}\text { Current } \\
\text { (Amps) }\end{array}$ & $\begin{array}{c}\text { Voltage } \\
\text { (Volts) }\end{array}$ & $\begin{array}{c}\text { Welding } \\
\text { speed } \\
\mathrm{mm} / \mathrm{min}\end{array}$ & $\begin{array}{c}\text { Heat } \\
\text { input } \\
\mathrm{kJ} / \mathrm{mm}\end{array}$ & \\
\hline T 10 & 1 & 675 & 35 & 420 & 3.37 & \\
T 15 & 1 & 780 & 38 & 400 & 4.45 & \\
T 20 & 1 & 850 & 40 & 400 & 5.10 & \\
T 20/2 & 2 & 690 & 25 & 400 & 2.58 & Leading wire \\
& & 650 & 35 & 400 & 3.40 & Trailing wire \\
\hline
\end{tabular}

Table 2 Welding parameters used to produce the single sided welds studied

\begin{tabular}{|c|c|c|c|c|c|c|c|c|c|c|c|c|c|c|c|c|c|c|c|}
\hline Weld & $\% \mathrm{C}$ & $\% \mathrm{Si}$ & $\% \mathrm{~S}$ & $\% \mathrm{P}$ & $\% \mathrm{Mn}$ & $\% \mathrm{Ni}$ & $\% \mathrm{Cr}$ & $\% \mathrm{Mo}$ & $\% \mathrm{Cu}$ & $\% \mathrm{Al}$ & $\% \mathrm{~N}_{2}$ & $\begin{array}{c}\text { 'DeLong } \\
\text { equivalents } \\
\mathrm{Cr}_{\text {eq }}\end{array}$ & $\mathrm{Ni}_{\text {eq }}$ & $\mathrm{Cr}_{\mathrm{eq}} / \mathrm{Ni}_{\mathrm{eq}}$ & $\begin{array}{c}\text { Predicted } \\
\% \text { ferrite }\end{array}$ & $\begin{array}{c}\text { "*Suutala } \\
\text { equivalents } \\
\mathrm{Cr}_{\text {eq }}\end{array}$ & $\mathrm{Ni}_{\mathrm{eq}}$ & $\mathrm{Cr}_{\mathrm{eq}} / \mathrm{Ni}_{\mathrm{eq}}$ & $\begin{array}{c}\text { Predicted } \\
\text { PSM } \\
\end{array}$ \\
\hline T 10 & 0.02 & 0.47 & 0.006 & 0.030 & 1.49 & 11.6 & 18.5 & 3.0 & 0.22 & 0.014 & 0.12 & 22.2 & 16.55 & 1.61 & 5 & 23.31 & 14.40 & 1.62 & $F-A$ \\
\hline T 15 & 0.02 & 0.51 & 0.006 & 0.034 & 1.42 & 11.6 & 18.2 & 2.9 & 0.24 & 0.013 & 0.12 & 21.9 & 16.5 & 1.57 & 5 & 22.94 & 14.64 & 1.57 & $F-A$ \\
\hline T 20 & 0.02 & 0.52 & 0.005 & 0.022 & 1.55 & 12.3 & 18.0 & 3.2 & 0.16 & 0.009 & 0.12 & 22.0 & 17.27 & 1.27 & 3.5 & 22.75 & 15.09 & 1.51 & $F-A$ \\
\hline T 20/2 & 0.03 & 0.52 & 0.003 & 0.020 & 1.53 & 12.2 & 18.4 & 3.1 & 0.17 & 0.010 & 0.12 & 22.2 & 17.46 & 1.27 & 3 & 23.43 & 15.21 & 1.54 & $F \cdot A$ \\
\hline Wire & 0.015 & 0.50 & 0.006 & 0.020 & 1.80 & 14.5 & 20.0 & 3.7 & n.d & n.d & 0.05 & & & & & 25.8 & 16.1 & $1 . .60$ & \\
\hline Plate & 0.02 & 0.43 & 0.005 & 0.028 & 1.55 & 11.3 & 18.1 & 2.9 & 0.24 & 0.010 & 0.15 & & & & & & & & \\
\hline
\end{tabular}

$-\mathrm{Cr}_{\mathrm{eq}}=\% \mathrm{Cr}+\% \mathrm{Mo}+1.5 \% \mathrm{Si}+0.5 \% \mathrm{Nb}$

$-\mathrm{Ni}_{\text {eq }}=\% \mathrm{Ni}+30 \% \mathrm{C}+30 \% \mathrm{~N} 2+0.5 \% \mathrm{Mn}$

$\cdot \mathrm{Cr}_{\text {eq }}=\% \mathrm{Cr}+1.37 \% \mathrm{Mo}+1.5 \% \mathrm{Si}+2 \% \mathrm{Nb}+3 \% \mathrm{Ti}$

$\cdot^{-\mathrm{Ni}_{\text {eq }}}=\% \mathrm{Ni}+0.31 \% \mathrm{Mn}+22 \% \mathrm{C}+14 \% \mathrm{~N} 2+\mathrm{Cu}$

Table 3 Chemical analysis ( $w t \%)$ for each of the welds : predicted delta ferrite values and predicted primary solidification modes (PSM) are also shown 


\begin{tabular}{|c|c|c|c|c|c|c|c|c|c|c|c|}
\hline \multirow[t]{3}{*}{ Weld } & \multirow{3}{*}{$\begin{array}{c}\text { Yield } \\
\text { strength } \\
\mathrm{N} / \mathrm{mm}^{2}\end{array}$} & \multirow{3}{*}{$\begin{array}{c}\text { Tensile } \\
\text { strength } \\
\mathrm{N} / \mathrm{mm}^{2}\end{array}$} & \multirow{3}{*}{$\begin{array}{c}\% \\
\text { Elongation }\end{array}$} & \multicolumn{4}{|c|}{ Absorbed energy $(\mathrm{J})$} & \multirow{2}{*}{\multicolumn{4}{|c|}{$\begin{array}{l}\text { Maximum weld } \\
\text { metal hardness }\end{array}$}} \\
\hline & & & & \multirow[t]{2}{*}{20} & \multirow[t]{2}{*}{-20} & \multirow[t]{2}{*}{-60} & \multirow[t]{2}{*}{-100} & & & & \\
\hline & & & & & & & & HAZ cap & WM cap & HAZ root & WM root \\
\hline T 10 & 318 & 585 & 46 & 135 & 123 & 114 & 88 & 193 & 171 & 173 & 175 \\
\hline Т 15 & 320 & 586 & 40 & 143 & 131 & 117 & 85 & 180 & 174 & 178 & 176 \\
\hline Т 20 & 319 & 592 & 43 & 110 & 96 & 67 & 44 & 186 & 179 & 197 & 192 \\
\hline T 20/2 & 336 & 609 & 43 & 78 & 99 & 75 & 42 & 203 & 197 & 197 & 205 \\
\hline
\end{tabular}

Table 4 Mechanical property and maximum hardness data for each of the welds.

\begin{tabular}{|c|c|c|c|}
\hline Welds & Austenite $\mathrm{H}$ & Delta ferrite $\mathrm{H}$ & Average $\mathrm{H}$ \\
\hline $\mathrm{T} 15$ & $189+/-9$ & 318 & $199+/-12$ \\
\hline
\end{tabular}

Table $5 \quad$ Microhardness data for $15 \mathrm{~mm}$ thick weld and estimated value for delta ferrite.

\begin{tabular}{|c|c|c|c|c|c|c|c|c|c|c|c|}
\hline & \multicolumn{11}{|c|}{ Specimens } \\
\hline Positions & B1 & B2 & B3 & B4 & B7 & F1 & F3 & F4 & F5 & F6 & F7 \\
\hline $\begin{array}{l}\text { Top of the weld } \\
\text { Mid-side of the weld } \\
\text { Bottom of the weld }\end{array}$ & $\mathbf{X}$ & $\mathrm{X}$ & $\mathbf{X}$ & $x$ & $\mathbf{x}$ & $\mathbf{X}$ & $\mathbf{X}$ & $\mathrm{X}$ & 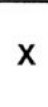 & $\mathrm{X}$ & X \\
\hline
\end{tabular}

\begin{tabular}{|c|c|c|c|c|c|c|c|c|c|c|c|c|c|}
\hline & \multicolumn{13}{|c|}{ Specimens } \\
\hline Positions & C1 & $\mathrm{C} 4$ & C5 & C7 & C9 & $\mathrm{C} 12$ & $\mathrm{D} 2$ & D3 & D4 & D5 & D6 & D7 & D8 \\
\hline $\begin{array}{l}\text { Top of the weld } \\
\text { Mid-side of the weld } \\
\text { Centre of the weld } \\
\text { Bottom of the weld }\end{array}$ & $\bar{x}$ & $\bar{x}$ & $\mathbf{x}$ & $\mathrm{X}$ & $x$ & $x$ & $\mathrm{X}$ & $\bar{x}$ & $\bar{x}$ & $x$ & $\mathrm{X}$ & $\mathrm{X}$ & $x$ \\
\hline
\end{tabular}




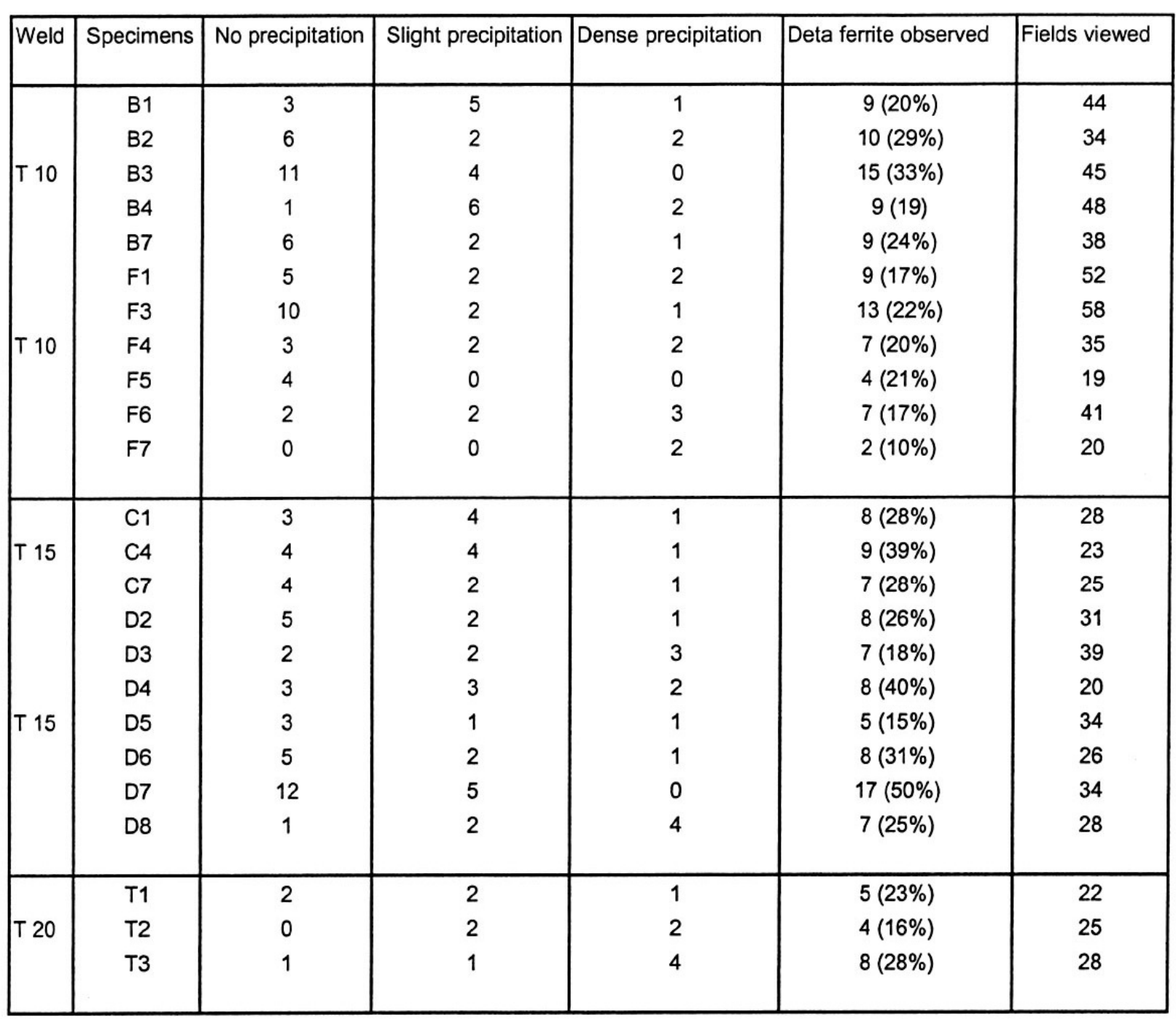

Table 8 Semi quantitative data for evidence of precipitation, and instances of delta ferrite presence. 

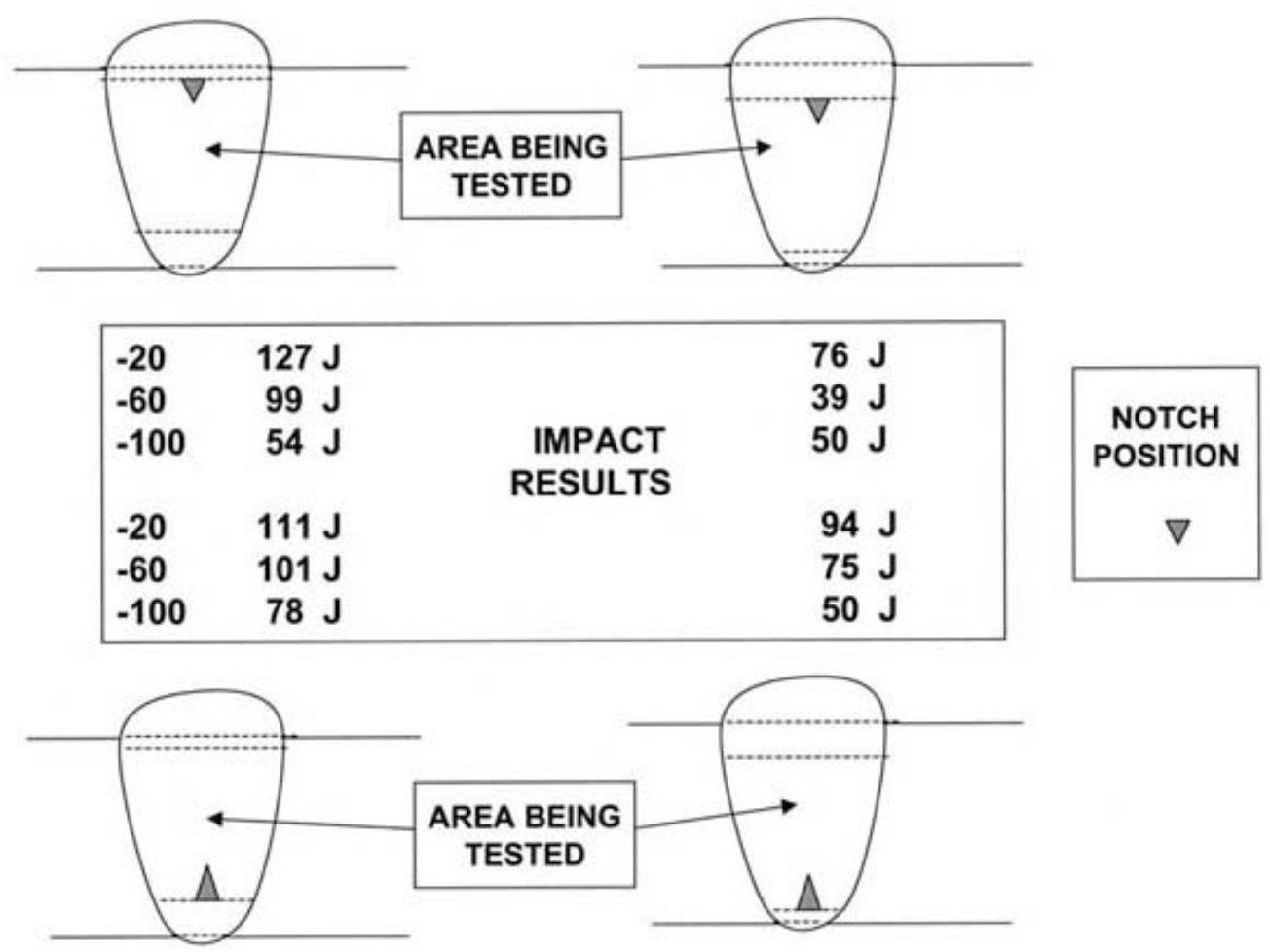

Figure 1 Positions of notches in $15 \mathrm{~mm}$ thick specimen for additional Charpy tests. 


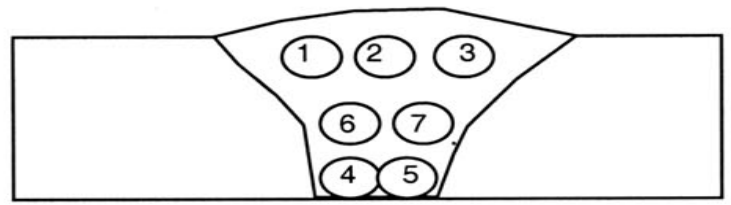

Specimen "B", from T10 (10 mm thick)

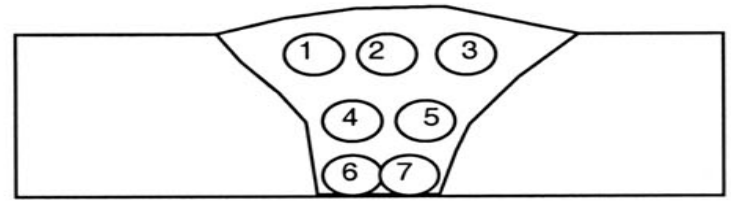

Specimen "F", from T10 (10 mm thick)

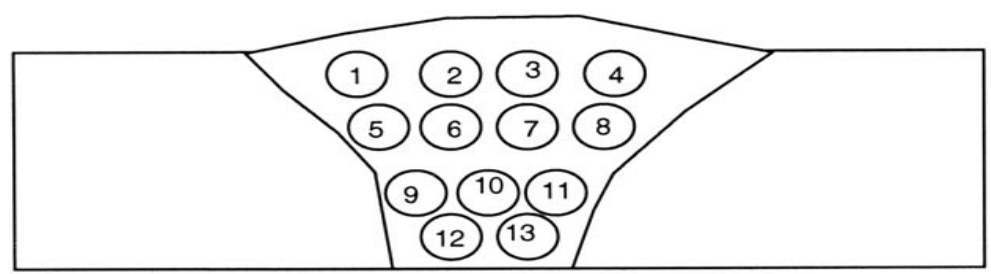

Specimen "C", from T15 (15mm thick)

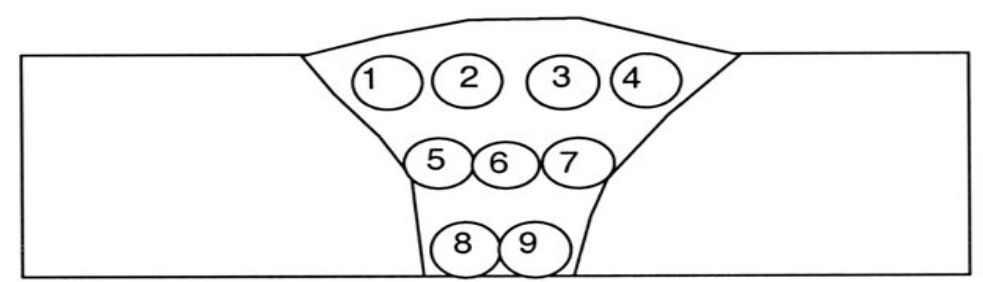

Specimen "D", from T15 (15mm thick)

Figure 2 Schematic representation of the position of TEM specimens 


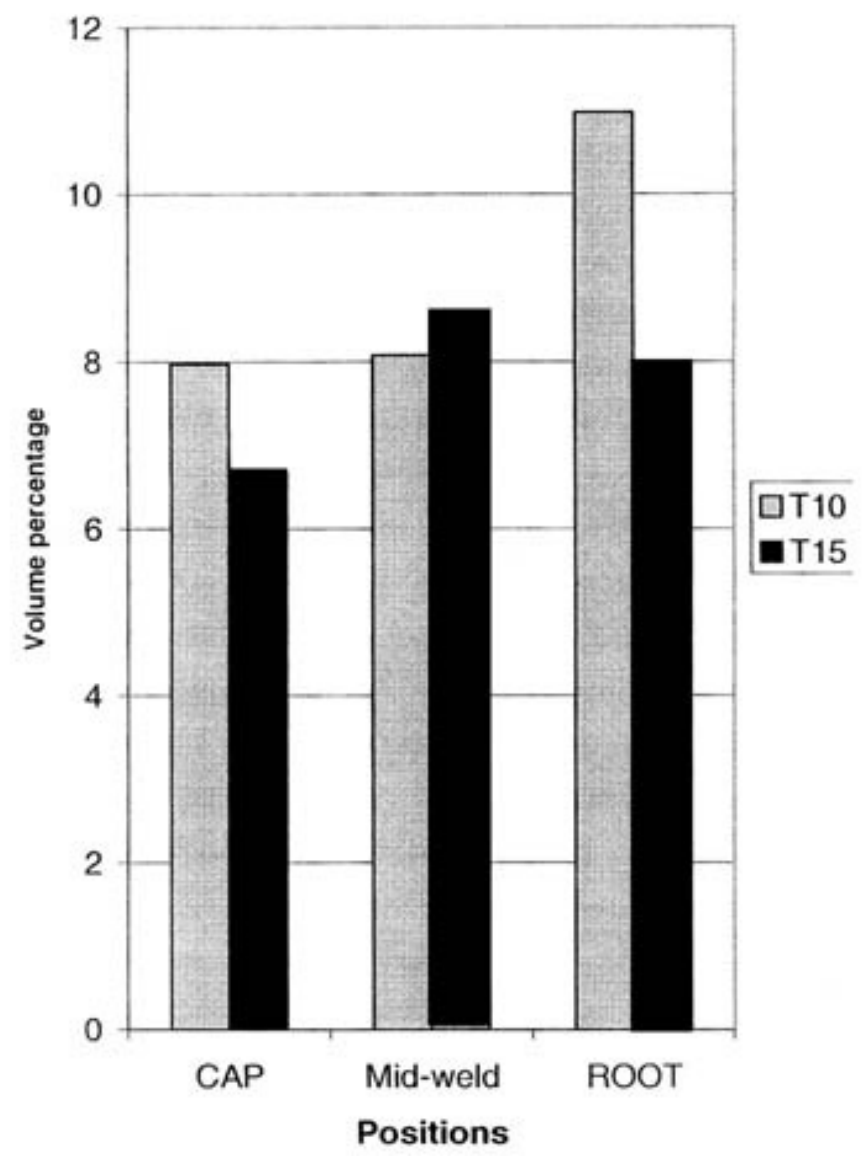

Figure 3 Ferrite volume fraction data related to position in the weld thickness for welds T10 and T15. 


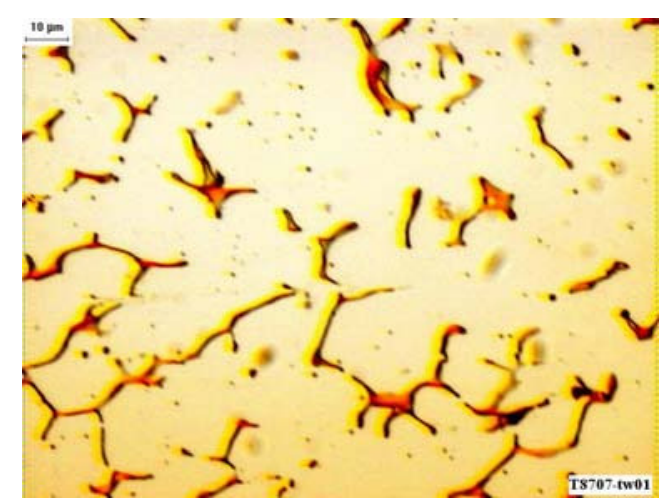

(a)

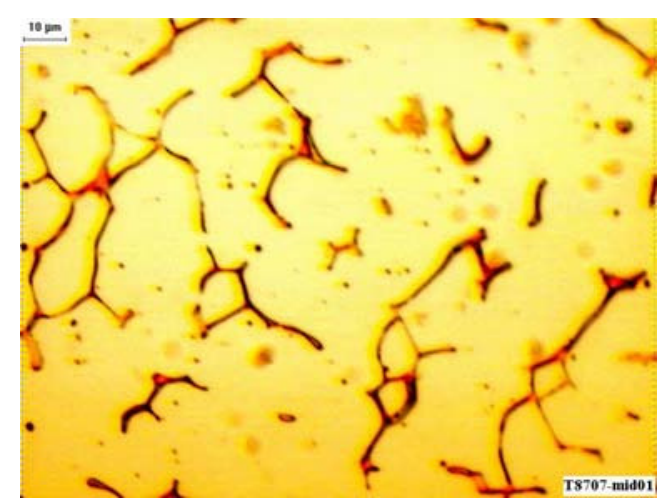

(b)



(c)

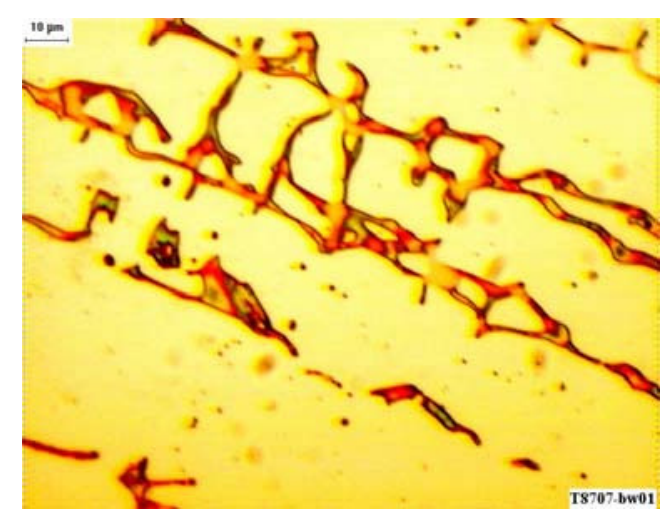

(d)

Figure 4 (a-d) Optical micrographs of delta ferrite in weld T10.

(a) Cap region, (b) Mid weld region, (c) \& (d) Root region 

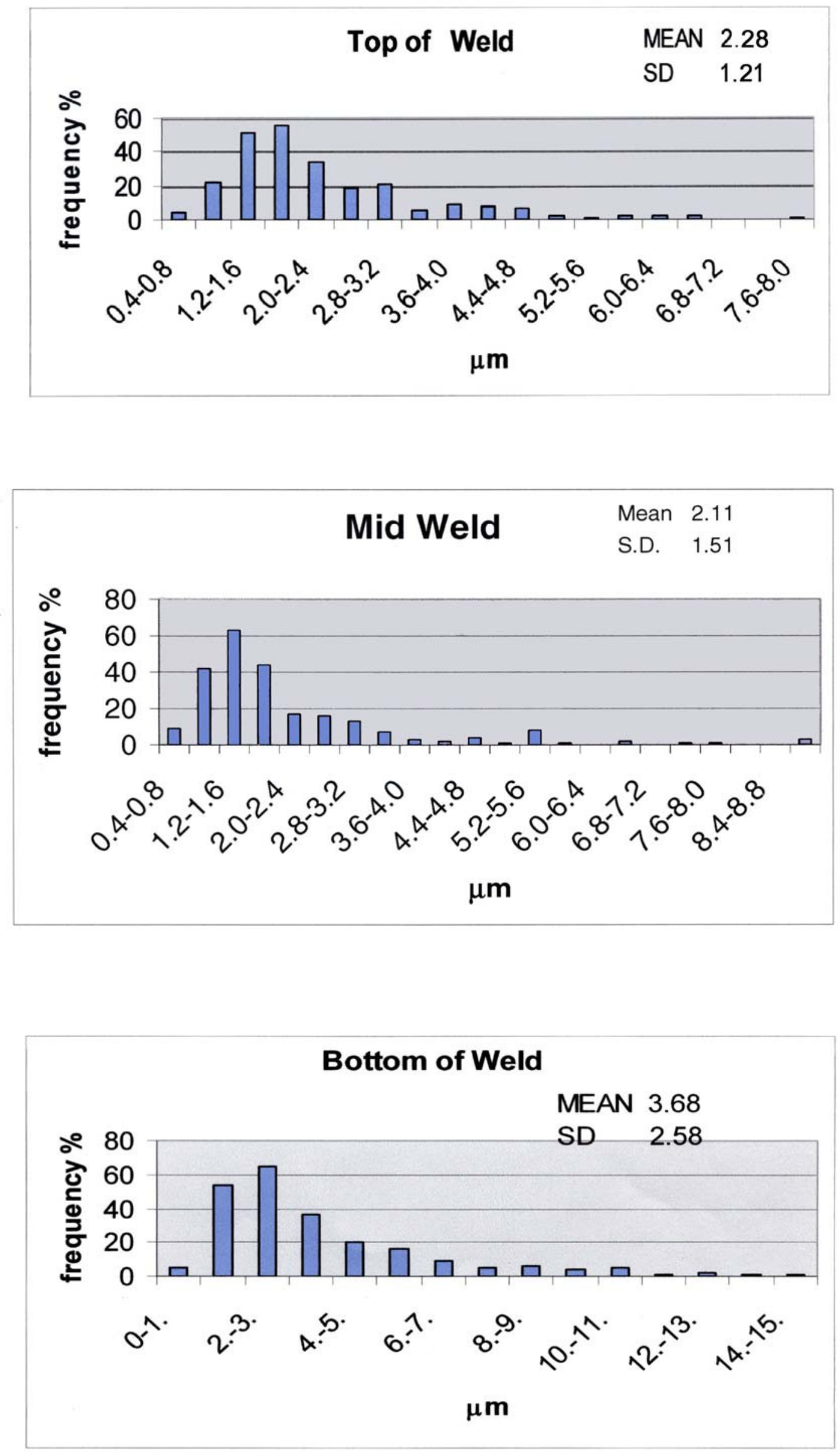

Figure 5 Delta ferrite thickness data for three positions through the thickness of weld T10. 


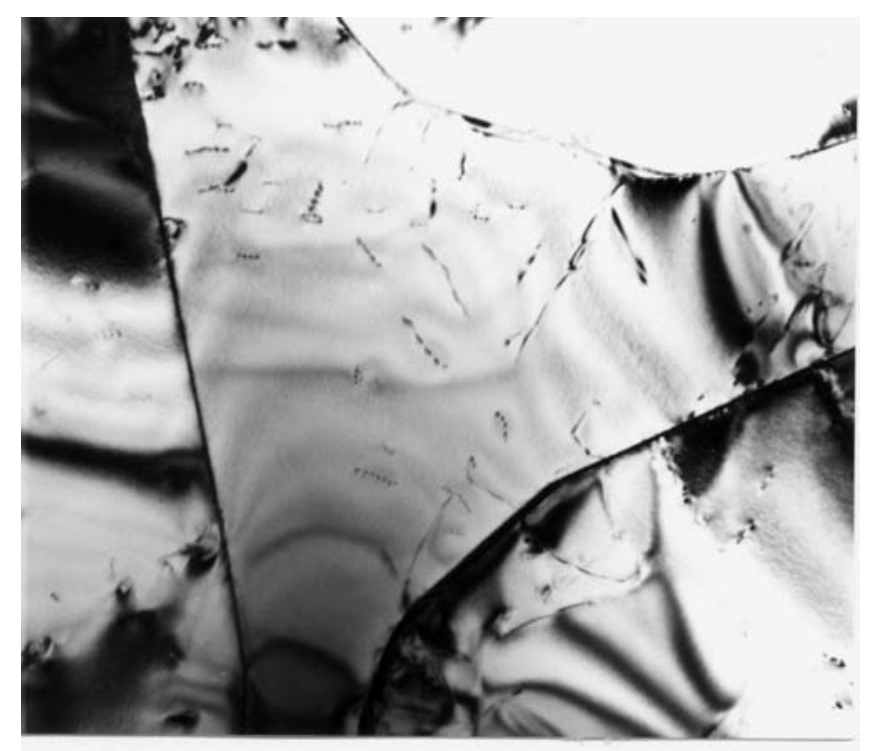

\section{$\underline{0.36 \mu \mathrm{m}}$}

Figure 6 TEM Bright field micrograph showing delta ferrite with virtually no precipitate

on the $\delta / \gamma$ grain boundary, in specimen $\mathrm{C} 1$, weld $\mathrm{T} 15$.



$\underline{0.45 \mu \mathrm{m}}$

Figure 7 TEM Bright field micrograph showing delta ferrite with slight precipitation on the $\delta / \gamma$ grain boundary, in specimen $\mathrm{C} 9$, weld $\mathrm{T} 15$. 


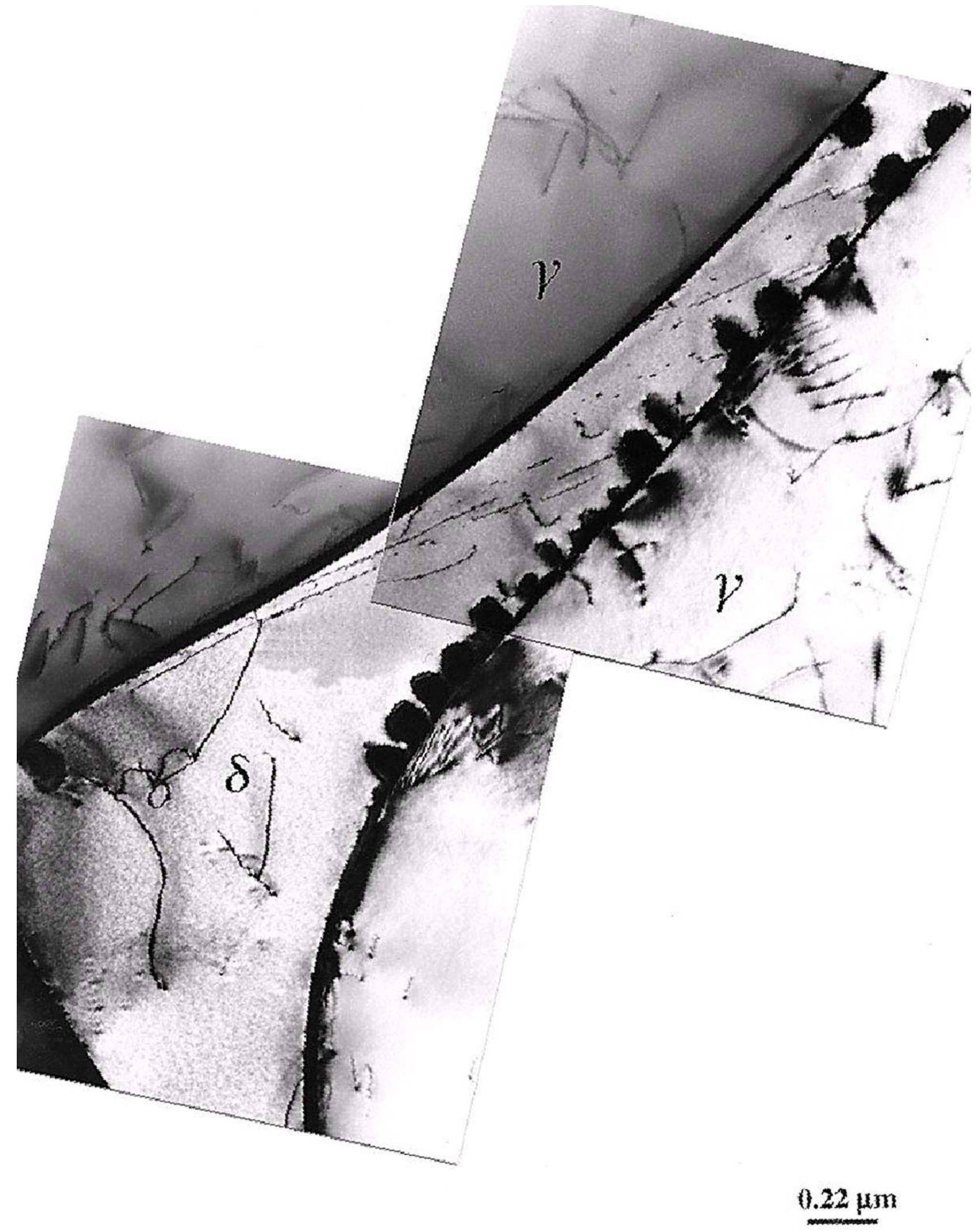

Figure 8 TEM Bright field micrograph showing delta ferrite with dense discontinuous precipitation 


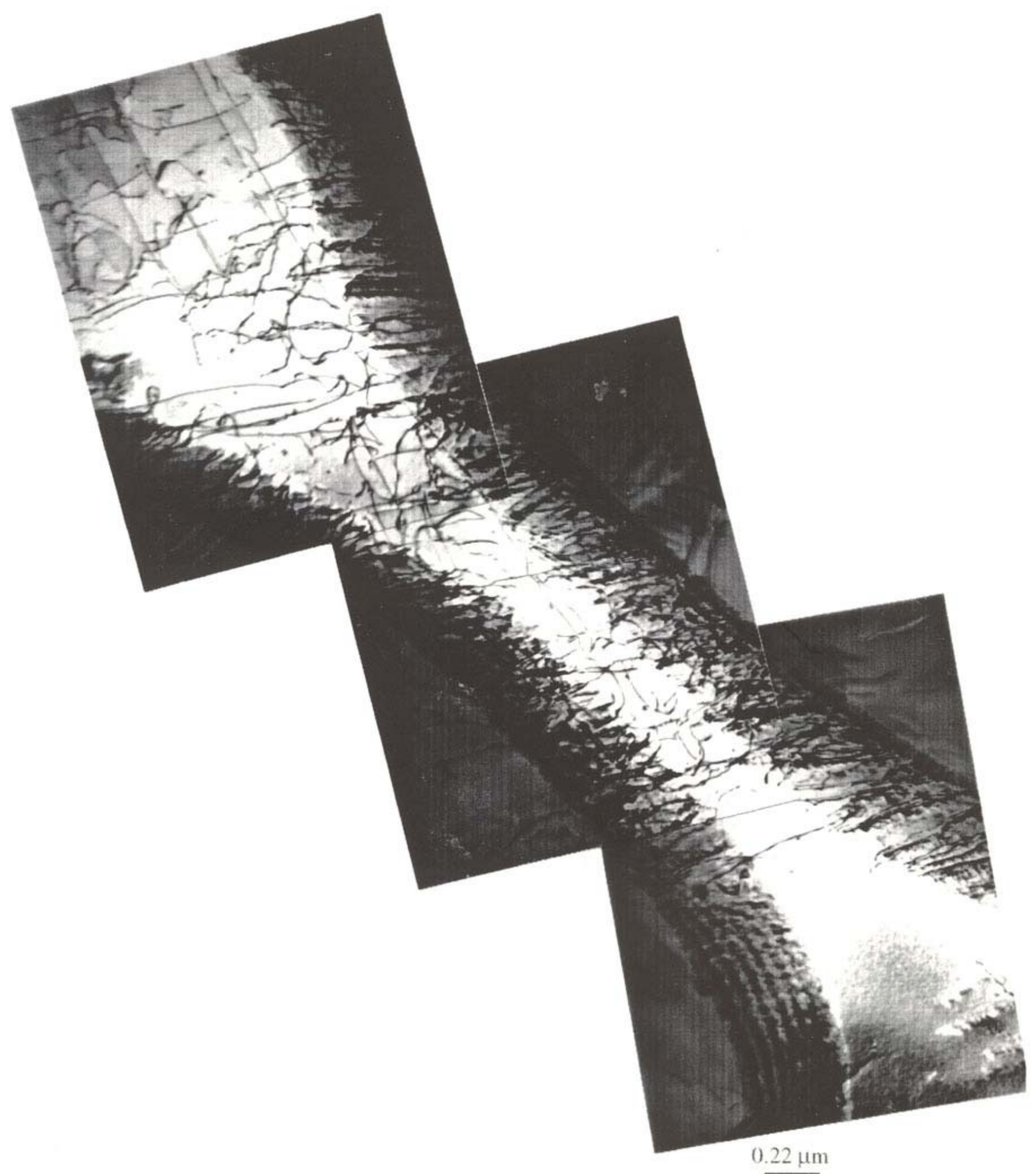

Figure 9 High dislocation density often seen in the absence of grain boundary precipitation 


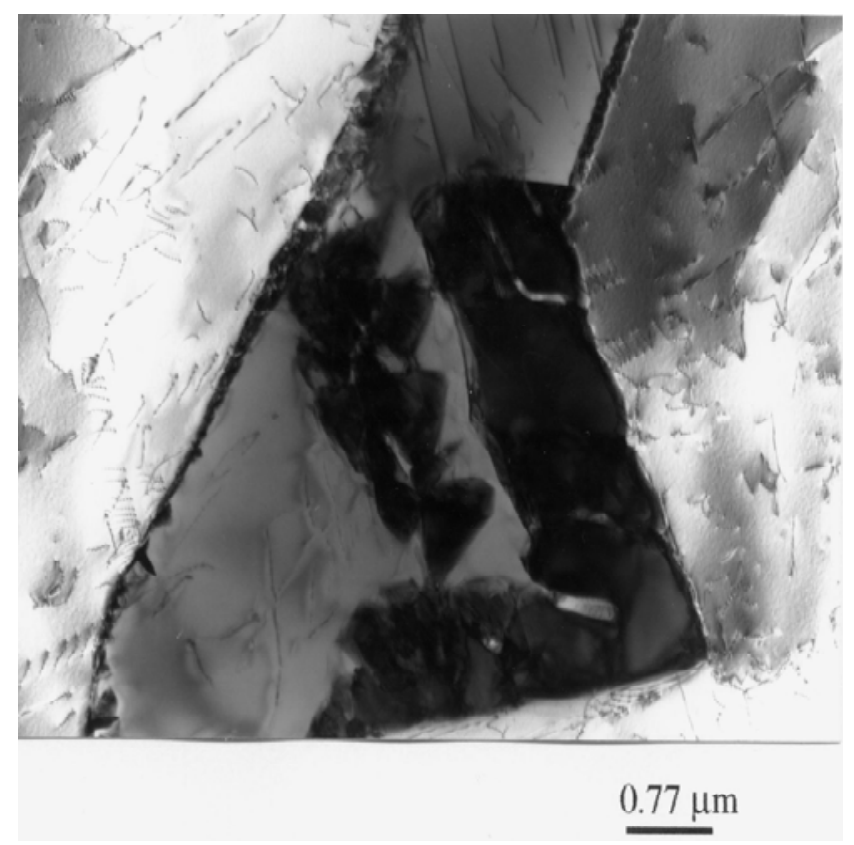

Figure 10 TEM bright field showing delta ferrite( dark grain) with significant $\sigma$ precipitation both along the $\delta / \gamma$ grain boundary and within the grain, in specimen F3, weld T10. 


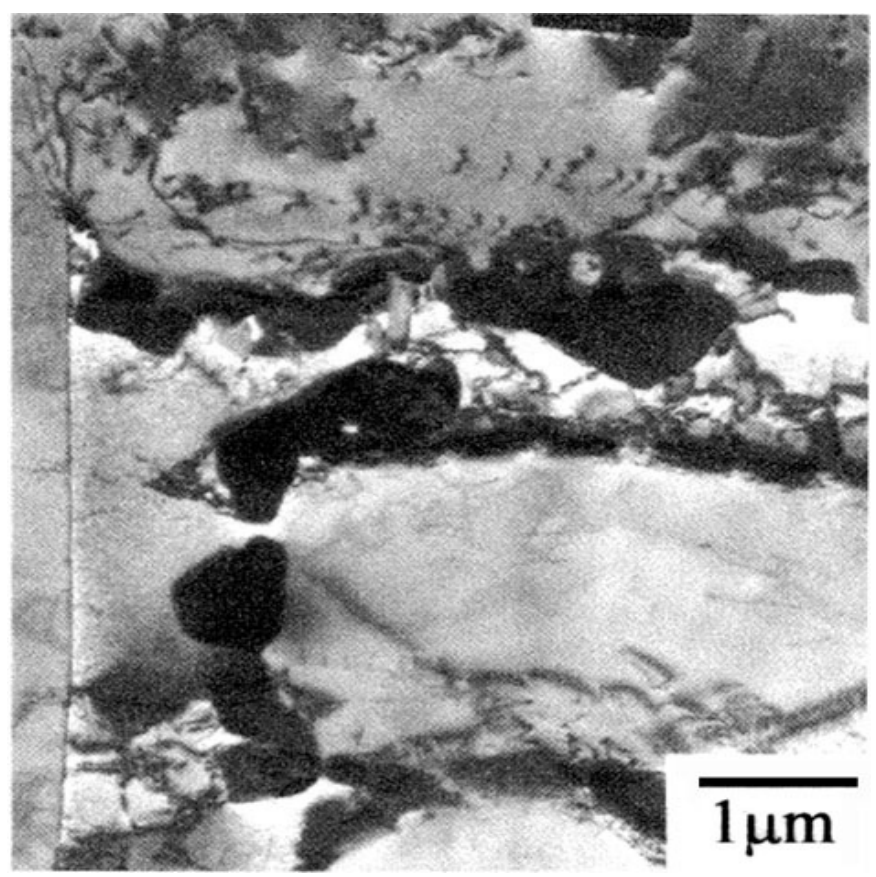

Figure 11 TEM bright field showing an area in weld T20/2 showing $\chi$ phase particles 


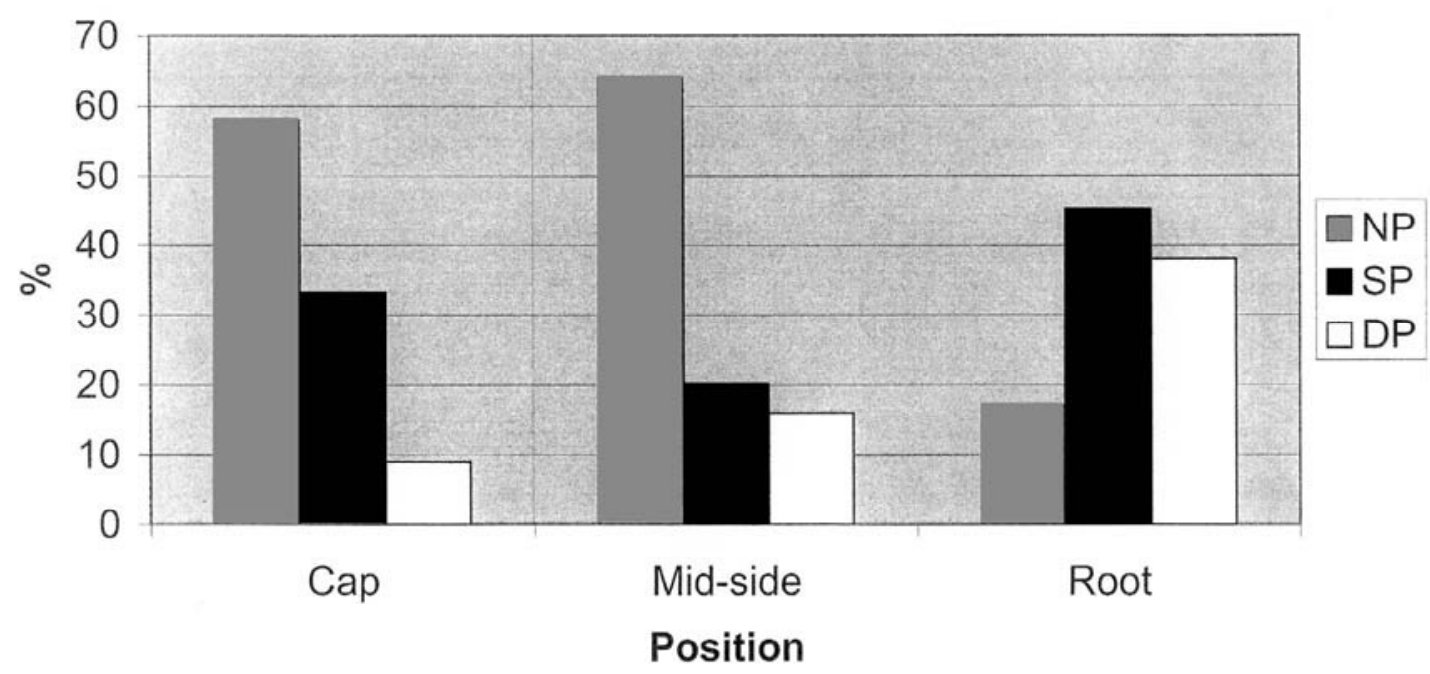

Figure 12 Semi-quantitative evaluation of intermetallic phase precipitation in T10 weld $\mathrm{NP}=$ no precipitate, $\mathrm{SP}=$ slight precipitate, $\mathrm{DP}=$ dense precipitate.

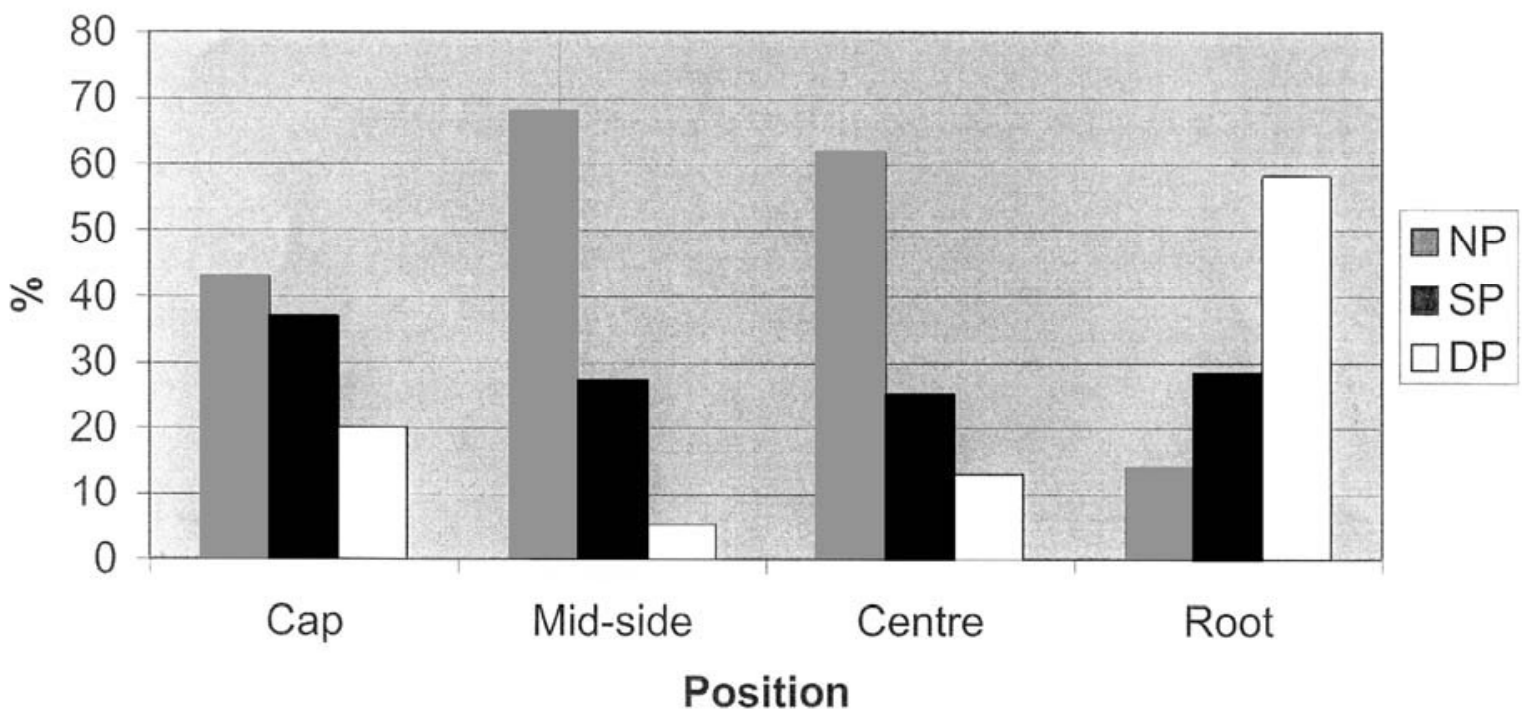

Figure 13 Semi-quantitative evaluation of intermetallic phase precipitation in T15 weld $\mathrm{NP}=$ no precipitate, $\mathrm{SP}=$ slight precipitate, $\mathrm{DP}=$ dense precipitate. 